\title{
COPPER RELEASE IN DRINKING WATER DUE TO INTERNAL CORROSION OF DISTIBUTION PIPES
}

\author{
M. FABBRICINO ${ }^{1, *}$ \\ A. PANICO ${ }^{1}$ \\ M. TRIFUOGGI ${ }^{2}$
}

Selected from papers presented in $9^{\text {th }}$ International Conference on Environmental Science and Technology (9CEST2005) 1-3 September 2005, Rhodes island, Greece

\author{
${ }^{1}$ University of Naples Federico II \\ Department of Hydraulic and Environmental Engineering \\ Girolamo Ippolito, Via Claudio 21, 80125 Naples, Italy \\ ${ }^{2}$ University of Naples Federico II \\ Department of Chemistry \\ Complesso Universitario di Monte Sant'Angelo \\ Via Cintia, 80125 Naples, Italy
}

*to whom all correspondence should be addressed Tel: +39-081-7683438; Fax: +39-081-5938936 e-mail: fabbrici@unina.it

\begin{abstract}
The present paper deals with water quality modification during its stagnation in copper distribution pipes caused by electrochemical corrosion processes. Copper is chosen as plumbing material because of its wide use in drinking water distribution systems all around the world, and because of its recognized toxicity at high dosages. Several experiments are developed, varying water composition and stagnation length, to ascertain the dependence of copper release on both parameters. The effect of different concentrations of bicarbonates, sulphates and phosphates on metal release is studied, assuming stagnation periods ranging from 15 to 90 minutes. The corrosion potential of the metal surface during stagnation episodes is also monitored to verify the existence of a direct correlation between this potential at the end of each stagnation episode, and the corresponding total dissolved copper concentration in the stagnating water. The correlation allows to quantify copper release in drinking water, measuring the corrosion potential, drastically reducing, in this way, the cost of water quality monitoring.
\end{abstract}

KEYWORDS: Copper, Corrosion, Drinking Water, Monitoring, Stagnation.

\section{INTRODUCTION}

In recent years electrochemical corrosion of copper distribution pipes has become a great concern for water utilities all over the world. Apart from water losses and damages related to pipe breaking, in fact, it has to be considered that copper release in drinking water can have other consequences on water utilisation and wastewater disposal. Copper contaminated water, in fact, is responsible for health disturbs such as abdominal pains, nausea, vomiting, diarrhea, headache, and drizziness (Sidhu et al., 1995), and is considered to be responsible for a particularly heavy form of liver cirrhosis, known as nonIndian childhood cirrhosis (Zietz et al., 2003). Moreover high copper concentration in drinking water determines a rapid deterioration of aluminium utensils and galvanized steel fittings (Feng et al., 1996a, 1996b), and makes it difficult the final disposal of sludges produced in wastewater treatment plants (Broo et al., 1997).

To keep under control the phenomenon, specific measures have been taken by the governments of many countries. In the USA the Environmental Protection Agency (EPA) promulgated, in 1991, the so called Lead and Copper Rule, fixing $1.3 \mathrm{mg} \cdot \cdot^{-1}$ as maximum 
admissible copper concentration in drinking water after 6 hours of stagnation. In Europe the Community Regulation promulgated in 1998 fixed a similar value $\left(2.0 \mathrm{mg} \cdot \cdot^{-1}\right)$, referring to stagnation periods established differently by each country, and ranging from 4 hours in Germany, to 12 hours in Denmark (Hoekstra et al., 2004).

Despite these considerations only a few studies have been developed to completely understand the phenomenon of copper release from water distribution pipes, and, therefore, the knowledge of the problem is still fragmentary.

The most important researches concern the effect of stagnation time (Merkel et al., 2002; Lytle and Schock, 2002) and water composition on copper release (Edwards et al., 1996; Broo et al., 1999; Edwards et al., 2002; Shin and Kim, 2004; Pehkonen et al., 2002), or deal with the possibility of predicting and mitigating the assumption of copper from drinking water (Broo et al., 1997, Lagos et al., 1999; Xiao et al., 2004, Kirmeyer et al., 2004).

Obtained data usually show a direct proportionality between copper concentration in stagnating water and stagnation length, at least for short stagnation periods, as for stagnation periods longer than $48 \mathrm{~h}$ the process seems to reach a plateau (Merkel et al., 2002). The effect of water quality characteristics, instead, is not clearly understood. Edwards et al. (2002) found that low phosphate concentration inhibits the corrosion process until the alkalinity is less than $300 \mathrm{mg} \cdot{ }^{-1}$ as $\mathrm{CaCO}_{3}$, whereas other experimental studies (Merkel et al., 2002) showed that alkalinity reduces the corrosion rate. In contrast with these findings, experimental results obtained in Florida showed a direct proportionality between water alkalinity and copper concentration in stagnating water (Xiao et al., 2004), pointing out also the beneficial effect of sulphates in reducing copper pipe corrosion. As far as concern the presence of chlorides, once more contrasting results have been obtained. Broo et al. (1997) found that the presence of chlorides tends to increase the phenomenon of copper release, while Pehkonen et al. (2002) showed that the corrosion process is somehow inhibited by high chloride concentration.

To better understand the effect of water quality characteristics on copper pipe corrosion, the present paper illustrates and discusses the results of an experimental study developed in laboratory controlled conditions. During experiments it is also measured the electrochemical potential of the corroding surface, to verify the existence of a direct relationship between this potential and the total dissolved copper concentration (Kirmeyer et al., 2004), which represents the fundamental equation for monitoring copper release in drinking water using a surrogate parameter, able to minimize the time and the cost of water quality control.

\section{MATERIALS AND METHODS CPSF theory}

The Corrosion Potential Stagnation Flow (CPSF) theory is based on the quantification of copper release in stagnating water due to corrosion processes, monitoring the electrochemical potential of the corroding surface.

Assuming that the corrosion process is caused only by dissolved oxygen, the copper oxidation current is defined by the following condition:

$i_{C u}+i_{O 2}=0$

where $i_{C u}$ is the copper oxidation current, and $i_{O 2}$ is the oxygen reduction current.

Coupling equation (1) with the Butler-Volmer expressions of $i_{\mathrm{Cu}}$ and $i_{\mathrm{O} 2}$, and considering the relationship between the electrochemical potential of an electrochemical couple $M_{O X} / M_{R E D}$ (oxidized form/reduced form) and the concentration of $M_{O x}$ in the water described by the Nernst equation, it is obtained the following expression of the corrosion potential: 


$$
\begin{aligned}
& E_{\text {corr }}=\frac{1}{\alpha_{1}+\beta_{2}}\left(\log \left(\frac{i_{1}}{i_{2}}\right)+\alpha_{1} E_{1}+\beta_{2} E_{2}-\beta_{2} \Phi p H\right)-\frac{0.5 \Phi \alpha_{1}}{\alpha_{1}+\beta_{2}} \log \Theta+ \\
& +\frac{0.25 \Phi}{\alpha_{1}+\beta_{2}}\left(2 \alpha_{1} \log \left[C u_{T O T}\right]+\left(\beta_{2}+\frac{4}{\Phi}\right) \log \left[C_{0}-0.5 C u_{T O T}\right]\right)
\end{aligned}
$$

where: $E_{\text {corr }}$ is the corrosion potential; $\alpha_{1}$ is the anodic Tafel slope for copper oxidation; $\beta_{2}$ is the cathodic Tafel slope for oxygen reduction; $i_{1}$ and $i_{2}$ are, respectively, the standard exchange current for oxygen reduction and the standard exchange current for copper oxidation; $E_{1}$ and $E_{2}$ are, respectively, the standard electrochemical potential for copper and the standard potential electrochemical for oxygen; $\Phi$ is the Nernst potential; $\Theta$ is the ratio between the total dissolved copper concentration, and the concentration of free copper; $\mathrm{Cu}_{T O T}$ is the total dissolved copper concentration and $C_{0}$ is the initial oxygen concentration.

Equation (2), which is valid for steady state conditions, neglecting the cathodic branch of the copper's Evans plot and the anodic branch of the oxygen's Evans plot, and assuming that free copper in completely in form of $\mathrm{Cu}^{++}$, is equivalent to the formal relationship:

$$
E_{\text {corr }}=\varepsilon_{0}+\mu \cdot \log \left[C u_{T O T}\right]
$$

where $\varepsilon_{0}$ and $\mu$ are numerical coefficients involving electrochemical constants and chemical parameters depending on water characteristics.

Equation (3) is the fundamental equation of the CPSF theory (Kirmeyer et al., 2004). It shows the existence of a direct correlation between the corrosion potential and the logarithm of the total copper concentration, and therefore allows the quantification of copper concentration in the water, measuring the corrosion potential, whenever the two coefficients $\varepsilon_{0}$ and $\mu$ are known or estimated.

\section{Experimentals}

Experiments were performed on a corrosion cell designed by the Civil and Environmental Engineering Department of the University of Washington (Kirmeyer et al., 2004). The cell (Figure 1) was made by two rectangular $30.5 \times 7.6 \times 0.64 \mathrm{~cm}$ copper plates, separated with a $1.5 \times 0.16 \mathrm{~cm}$ thick plastic gasket. In this way it was created a thin rectangular channel through which the water could flow or stagnate. The internal volume of the cell was about $200 \mathrm{ml}$, which corresponded also to the volume of water exposed to copper release during stagnation. The area of the metal in contact with water was $245 \mathrm{~cm}^{2}$.

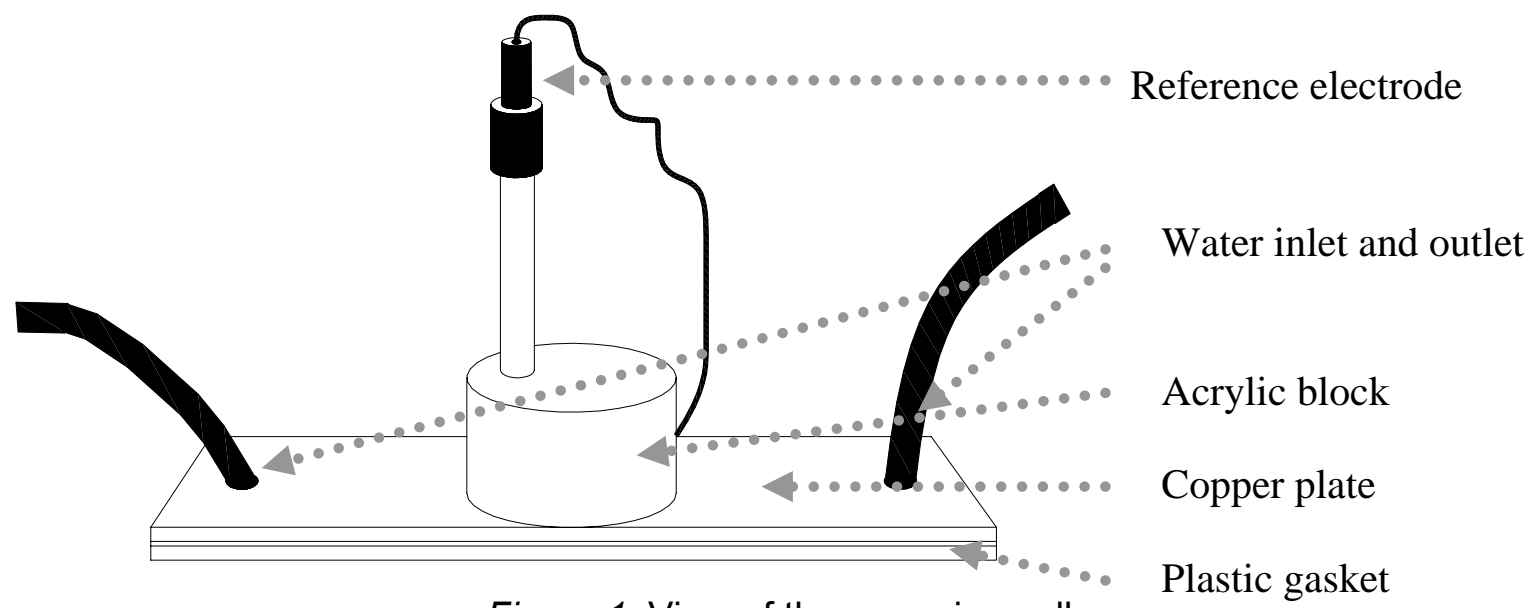

Figure 1. View of the corrosion cell 
A double junction standard calomel reference electrode (Beckman Instrument Inc., Model 511105) used to measure the electrochemical potential of the corroding surface was inserted in the middle of the upper copper plate and supported by an acrylic block.

All experiments were performed using synthetic water, prepared adding chemical reagents high purity degree to deionised water (Millipore, model Rios 30). Sodium sulphate and sodium bicarbonate were utilised, respectively, as source of sulphates and bicarbonates, while dibasic sodium phosphate $\left(\mathrm{Na}_{2} \mathrm{HPO}_{4}\right)$ was used as source of phosphates.

The water was pumped through the cell from a HDPE plastic tank using a peristaltic pump (KNF, model ND $100 \mathrm{KT} .18$ ). The flow rate was set to $0.8 \mathrm{I} \cdot \mathrm{minutes}^{-1}$ and controlled using a pump speed controller (Figure 2).

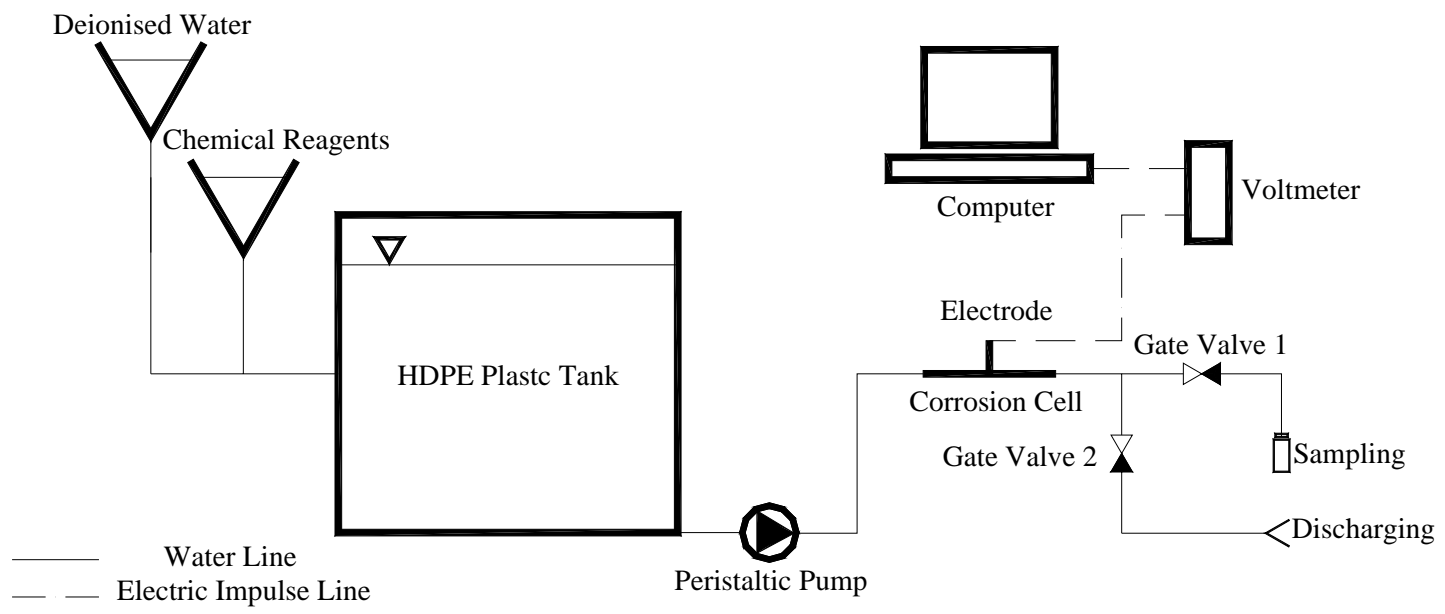

Figure 2. Experimental plant

A stagnation/flow sequence (Figure 3), characterized by varying stagnation periods, was adopted to identify the effect of stagnation time on copper release.

The length of the flow time was fixed to 30 minutes, in order to wash the internal surface of the cell and remove the layers of corrosion scales eventually formed during stagnation.

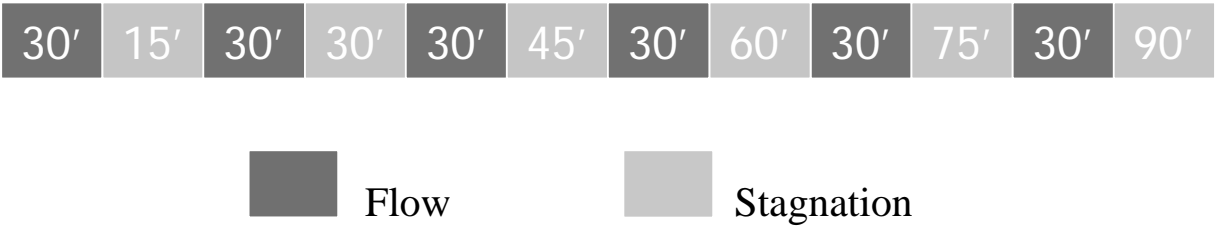

Figure 3. Adopted stagnation/flow sequence

During each stagnation episode the electrochemical potential value of the corroding metal surface was acquired on-line with a portable voltmeter, and stored on computer. Immediately after each stagnation episode, $250 \mathrm{ml}$ of water were sampled and stored for subsequent analyses. $50 \mathrm{ml}$ of each sample were used to measure the value of temperature and $\mathrm{pH}$, whereas the remaining $200 \mathrm{ml}$ were used for metal detection: this latter was effectuated with an atomic absorption spectrometer (Varian, model SpectrAA). Eleven series of tests were performed, varying water composition as shown in Table 1. All analyses were performed according to international analytical methods. 
Table 1. Water composition during experiments

\begin{tabular}{c|c}
\hline Test ID & Anions \\
\hline B1 & $\mathrm{HCO}_{3}^{-}=\left.25 \mathrm{mg} \cdot\right|^{-1}$ \\
B2 & $\mathrm{HCO}_{3}^{-}=50 \mathrm{mg} \cdot \cdot^{-1}$ \\
B3 & $\mathrm{HCO}_{3}^{-}=100 \mathrm{mg} \cdot l^{-1}$ \\
B4 & $\mathrm{HCO}_{3}^{-}=200 \mathrm{mg} \cdot l^{-1}$ \\
B5 & $\mathrm{HCO}_{3}^{-}=400 \mathrm{mg} \cdot \cdot^{-1}$ \\
S1 & $\mathrm{SO}_{4}^{-2}=\left.2 \mathrm{mg} \cdot\right|^{-1}$ \\
S2 & $\mathrm{SO}_{4}^{-2}=4 \mathrm{mg} \cdot \cdot^{-1}$ \\
S3 & $\mathrm{SO}_{4}^{-2}=8 \mathrm{mg} \cdot l^{-1}$ \\
P1 & $\mathrm{PO}_{4}^{-3}=0.5 \mathrm{mg} \cdot l^{-1}$ \\
P2 & $\mathrm{PO}_{4}^{-3}=1 \mathrm{mg} \cdot l^{-1}$ \\
P3 & $\mathrm{PO}_{4}^{-3}=2 \mathrm{mg} \cdot l^{-1}$ \\
\hline
\end{tabular}

\section{RESULTS}

Experimental data concerning copper release for different stagnation times and different bicarbonate concentrations are summarized in Figure 4. For each stagnation time it can be noted that copper release decreases increasing bicarbonate concentration. For each bicarbonate concentration, instead, it can be observed that copper release initially increases increasing stagnation time and, afterwards, tends to reach a plateau. These trends are in agreement with the formation of two superposed layers on the corroding metal surface, composed, respectively, by malachite, $\mathrm{Cu}_{2}(\mathrm{OH})_{2}\left(\mathrm{CO}_{3}\right)_{2}$, and tenorite, $\mathrm{CuO}$, (Shin and Kim, 2004). The layers, in fact, represent an obstacle to oxygen diffusion, and inhibit copper release. Therefore after their formation, copper concentration in stagnating water becomes function of the dynamic equilibrium established between precipitation and dissolution of $\mathrm{Cu}_{2}(\mathrm{OH})_{2}\left(\mathrm{CO}_{3}\right)_{2}$ and $\mathrm{CuO}$, and does not increase anymore increasing stagnation time. As it can be easily noted the formation of the protective layer is reached in about one hour for low values of bicarbonates concentration $\left(25-50 \mathrm{mg} \cdot \mathrm{l}^{-1}\right)$ and in about half time for higher values $\left(>100 \mathrm{mg} \cdot \mathrm{l}^{-1}\right)$.

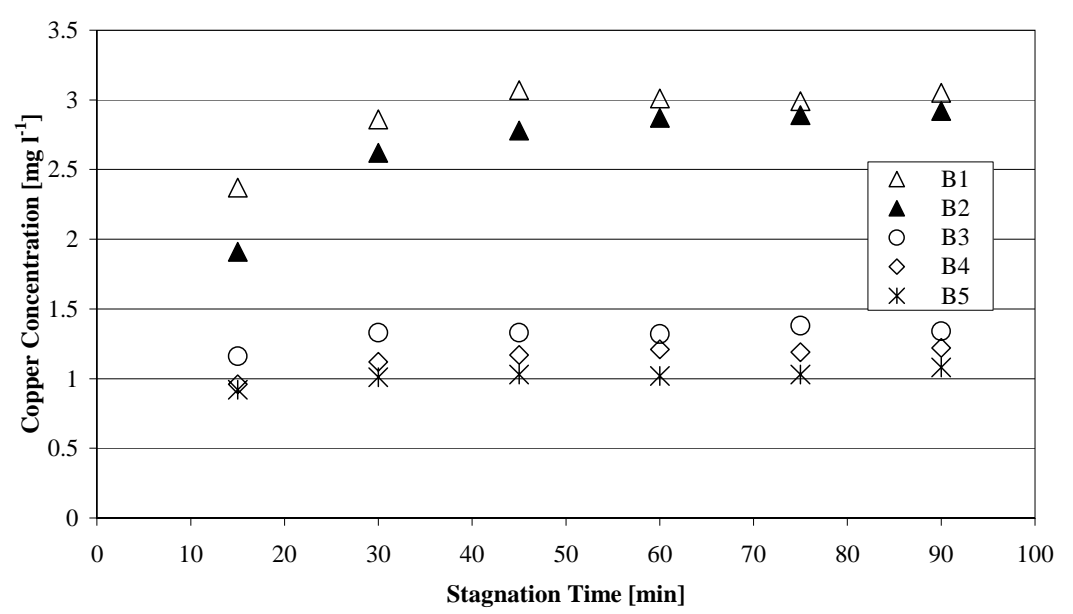

Figure 4. Copper concentration varying stagnation time and bicarbonate concentration

The effect of sulphates (Figure 5) and phosphates (Figure 6) on copper release is somehow analogous. For an assigned stagnation time, in fact, copper release decreases increasing sulphates or phosphates concentration. For each concentration of sulphates and phosphates, instead, metal release tends to increase increasing the length of the stagnation episode, reaching a plateau when a threshold value of stagnation time is passed. These threshold values, within the range of tested conditions, are around 30 minutes in presence of sulphates (Figure 5) and around $1 \mathrm{~h}$ in presence of phosphates 
(Figure 6). Differences existing among Figures 4, 5 and 6, can be attributed to the difference porosity of the insoluble compounds which are formed as consequence of the reactions occurring between copper ions and the other dissolved species (Shin and Kim, 2004).

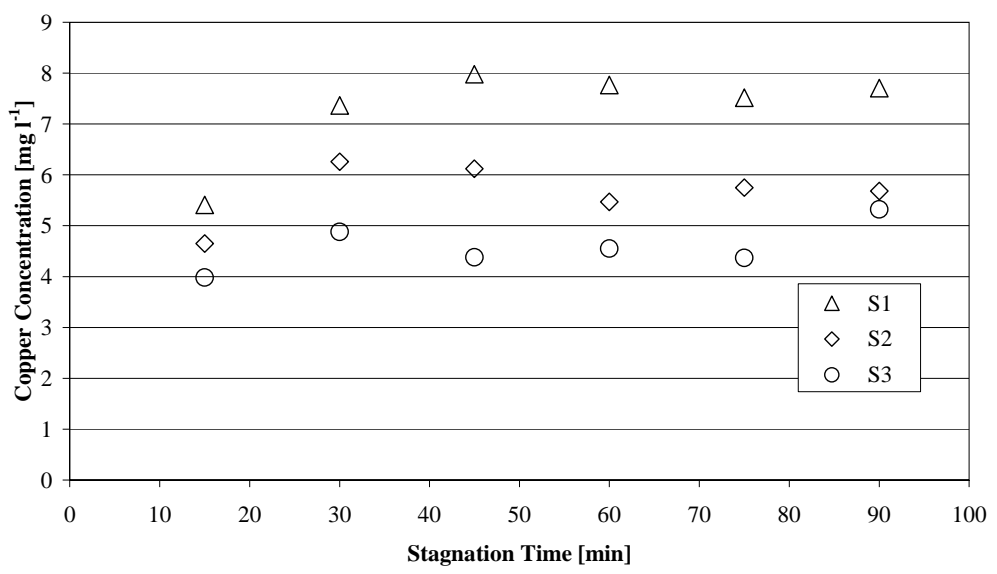

Figure 5. Copper concentration varying stagnation time and sulphate concentration

The corrosion potential trend during the stagnation/flow sequence is represented in Figures 7, 8 and 9. During stagnation episodes $E_{\text {corr }}$ exhibits a characteristic and reproducible trend whatever is the composition of the stagnating water. At the beginning of each stagnation episode, in fact, $E_{\text {corr }}$ drastically decreases, reaching a minimum which is more pronounced for lower water salinity. After that, it tends to slightly increase, reaching, once more, the initial value, and sometimes even passing it. Moreover values measured at the beginning of stagnation or after a certain time are not function of the considered stagnation episode, depending exclusively on the type and the concentration of the dissolved anions. Particularly an increase of anion concentration causes a shift of the experimental curves towards less negative corrosion potentials.

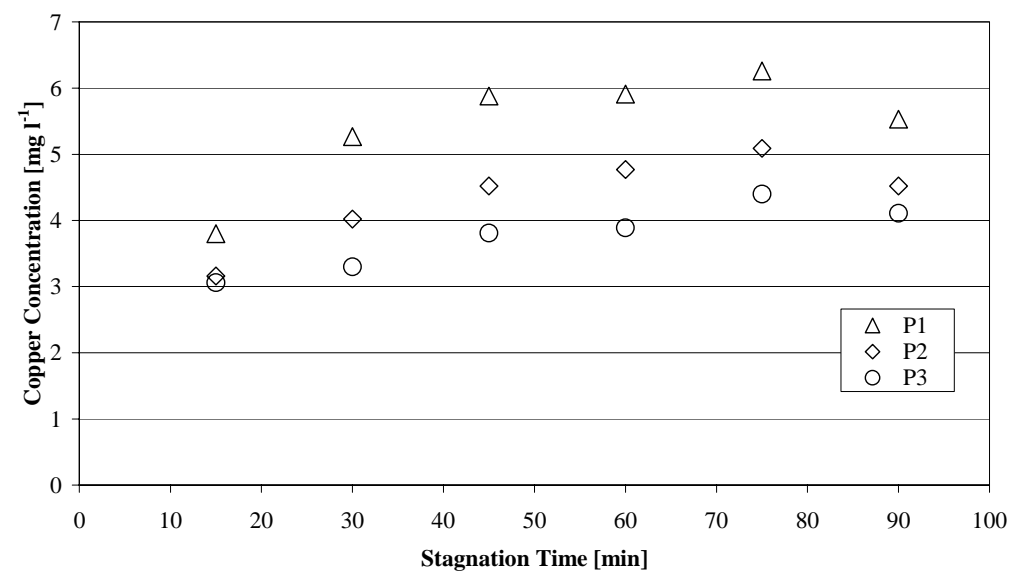

Figure 6. Copper concentration varying stagnation time and phosphate concentration 


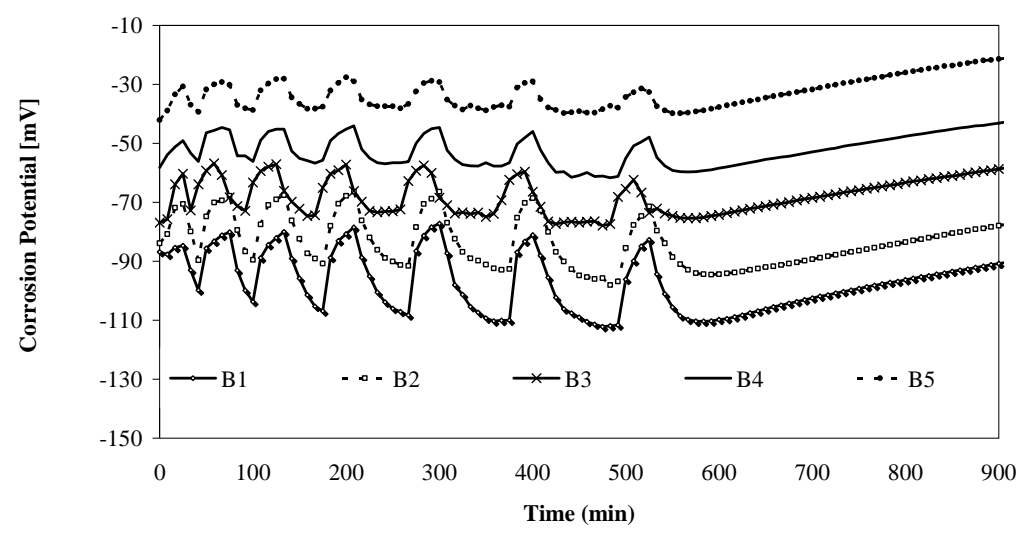

Figure 7. Corrosion potential varying bicarbonates concentration

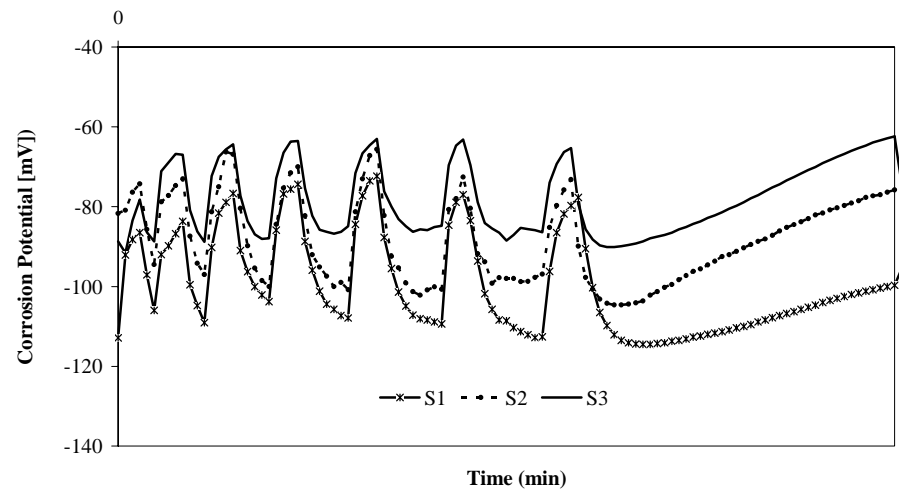

Figure 8. Corrosion potential varying sulphate concentration

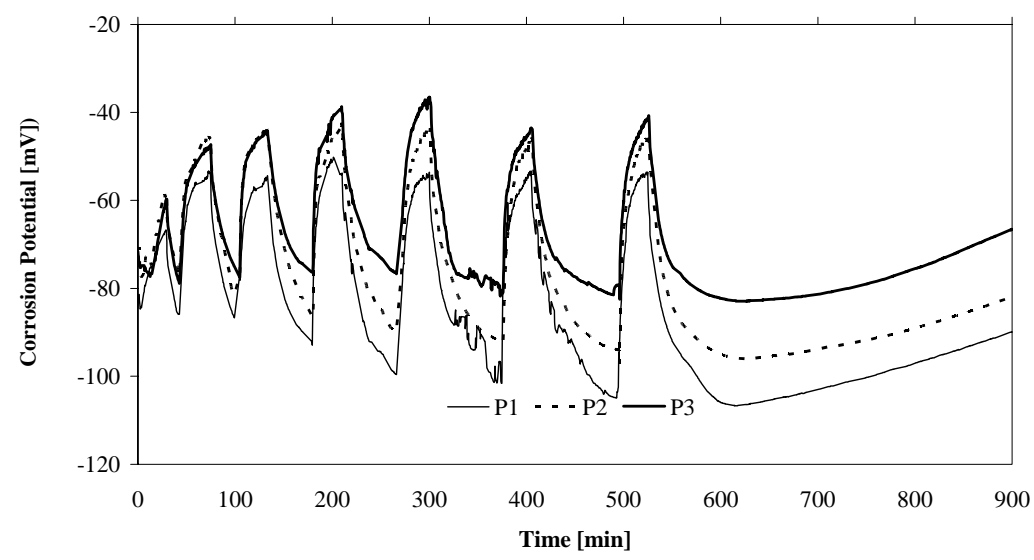

Figure 9. Corrosion potential varying phosphate concentration

Data reported in all the over mentioned figures make it possible to obtain a relationship between the corrosion potential at the end of each stagnation episode, and the corresponding concentration of copper in the stagnating water.

As it can be noted from Figures 10, 11 and 12, correlation coefficients $\left(R^{2}\right)$ of the linear curves interpolating the experimental data in a semi-logarithmic scale are not less than 0.81 , whatever is the tested water composition. It can be therefore assumed that 0 and 
values are, respectively, $-49 \mathrm{mV}$ and $-50 \mathrm{mV} \cdot \mathrm{l} \cdot \mathrm{mg}^{-1}$ for water containing bicarbonates, -32 $\mathrm{mV}$ and $-37 \mathrm{mV} \cdot \mathrm{l} \cdot \mathrm{mg}^{-1}$ for water containing sulphates, and $-22 \mathrm{mV}$ and $-43 \mathrm{mV} \cdot \mathrm{l} \cdot \mathrm{mg}^{-1}$ for water containing phosphates, and equation (3) can be used for monitoring copper concentration in stagnating water, simply measuring the corrosion potential.

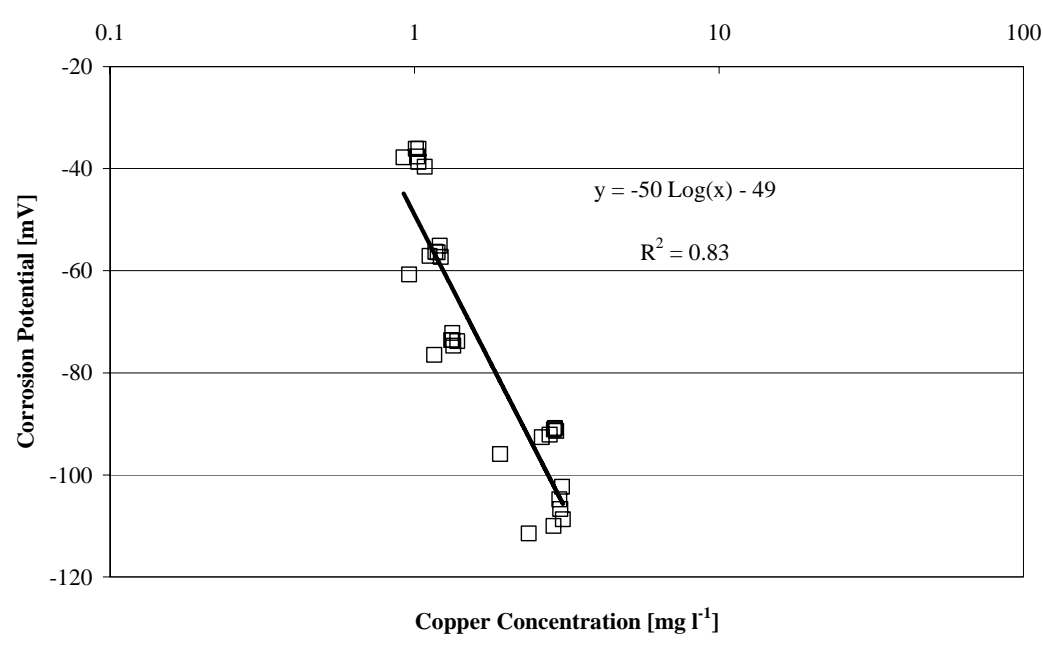

Figure 10. Water containing bicarbonates: relationship between $E_{c o r}$ and $\log (\mathrm{Cu})$

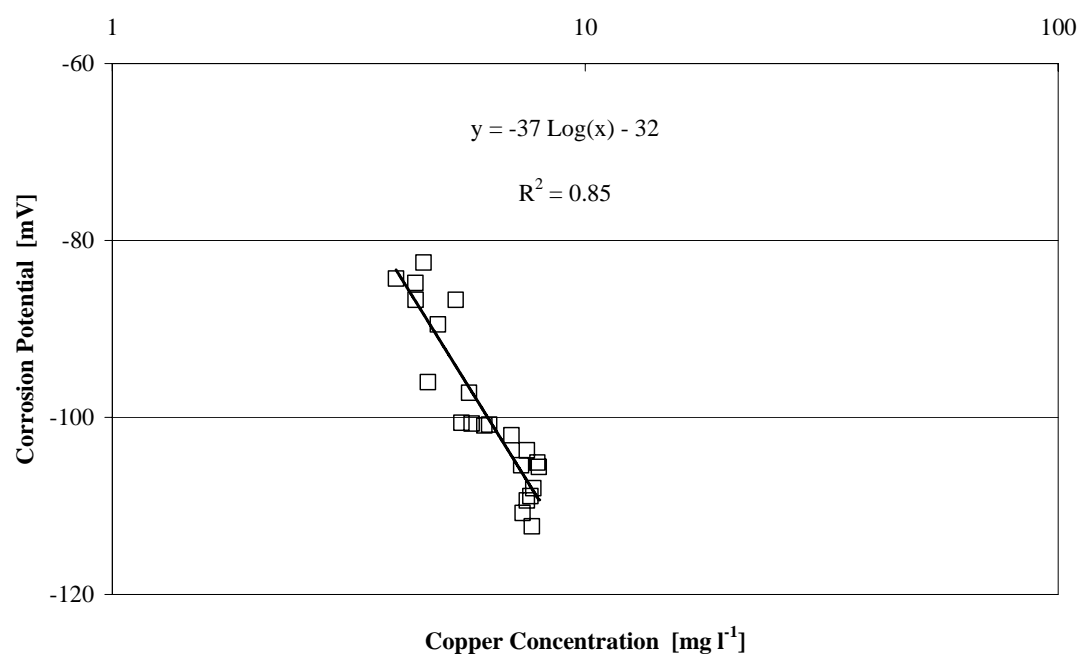

Figure 11. Water containing sulphates: relationship between $E_{\text {corr }}$ and $\log (\mathrm{Cu})$

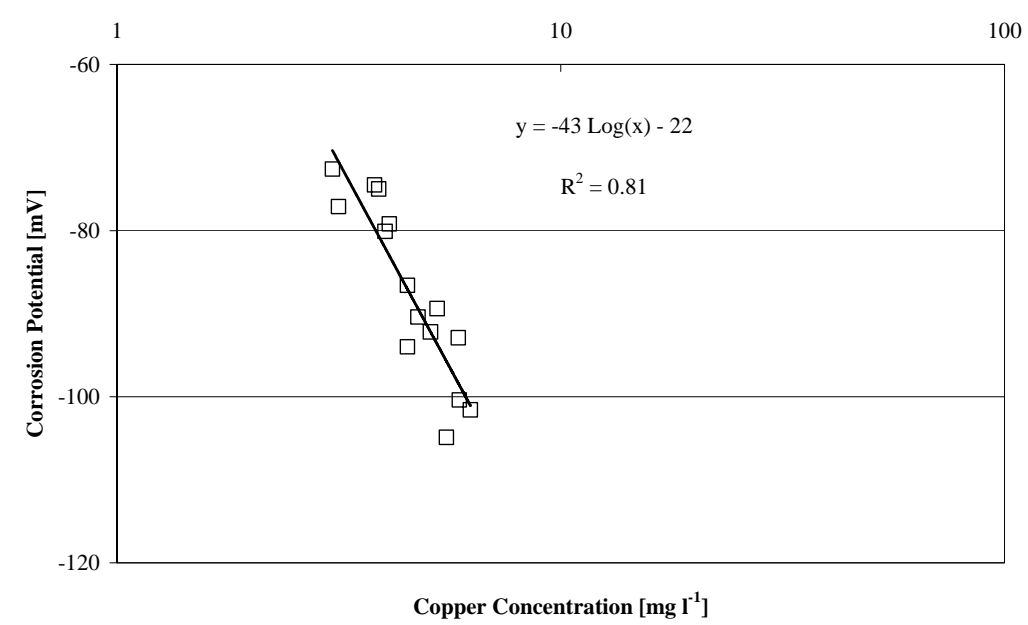

Figure 12. Water containing phosphates: relationship between $E_{c o r r}$ and $\log (\mathrm{Cu})$ 


\section{CONCLUSIONS}

The principal results of the presented research study can be summarized as follows:

- during water stagnation in copper distribution pipes, metal ions can be released as consequence of the development of electrochemical corrosion processes. The amount of metal release is not negligible and contributes to water quality modification;

- water composition drastically affects copper release; depending on water composition, in fact, copper ions can form insoluble compounds which precipitate on metal surface, reducing the corrosion rate;

- a surrogate parameter can be used for copper concentration monitoring during water stagnation, minimizing costs and times required for water quality control: this parameter is represented by the corrosion potential measured at the end of stagnation periods, which is well correlated with copper concentration, as predicted by the CPSF theory.

Further studies are, of course, necessary to understand the effect of the contemporary presence of several anions, on both the corrosion potential trend and the copper release amount.

\section{REFERENCES}

Sidhu K.S., Nash D.F. and McBride D.E. (1995), Need to Revise the National drinking Water Regulation for Copper, Regulatory Toxicol. and Pharmacol., 22, 95-100.

Zietz B.P., Dieter H.H., Lakomek M., Shneide H., Kebler-Gaedtke B. and Hartmut D. (2003), Epidemiologic Investigation on Chronic Copper Toxicity to Children Exposed via the Public Drinking Water Supply, The Science of The Total Environment, 302, 127-144.

Feng Y., Teo W.-K., Siow K.-S., Tan K.-L. and Hsieh A.-K.(1996a), The Corrosion Behaviour of Copper in Neutral Tap Water. Part I: Corrosion mechanisms, Corrosion Science, 38, 369385.

Feng Y., Teo W.-K., Siow K.-S. and Hsieh A.-K. (1996b), The Corrosion Behaviour of Copper in Neutral Tap Water. Part II: Determination of Corrosion Rates, Corrosion Science, 38, 387395.

Broo A.E., Berghult B. and Hedberg T. (1997) Copper Corrosion in Drinking Water Distribution System - The influence of Water Quality, Corrosion Science., 39, 1119-1132.

Hoekstra E.J., Pedroni V., Passerella R., Trincherini P.R. and Eisenreich S.J. (2004), Elements in Tap Water. Part 3. Effect of Sample Volume and Stagnation Time on the Concentration of the Element, IES, Italy.

Merkel T.H., Groß H.-J., Werner W., Dahlke T., Reicherter S., Beuchle G. and Eberle S.H. (2002), Copper Corrosion By-product Release in Long-term Stagnation Experiments, Water Research, 36, 1547-1555.

Lytle D.A. and Schock M.R. (2002) Impact of Stagnation Time on Metal Dissolution from Plumbing materials in Drinking Water., J. Water Supply Res. Technol.-Aqua, 49, 243-257.

Edwards M.A., Meyer T.E., Rehring J., Ferguson J.F., Korshin G.V. and Perry S.A. (1996) Role of Inorganic Anions, NOM and Water Treatment Processes in Copper Corrosion, AWWARF and AWWA, Denver, CO.

Broo A.E., Berghult B. and Hedberg T. (1999) Drinking Water Distribution - The Effect of the Natural Organic Matter (NOM) on the Corrosion of Iron and Copper, Water Sci. Technol., 40, $17-24$.

Edwards M., Hidmi L. and Gladwell D. (2002), Phosphate Inhibition of Soluble Copper Corrosion By-product Release, Corrosion Science, 44, 1057-1071.

Shin J.J. and Kim J.G. (2004) Copper Corrosion in Potable Water Distribution Systems: Influence of Copper Products on the Corrosion Behaviour, Materials Letters, 58, 2002-2006.

Pehkonen S.O., Palit A. and Zhang X. (2002) Effect of Specific Water Quality Parameters on Copper Corrosion, Corrosion, 58, 156-165.

Lagos G.E., Maggi L. C., Peters D. and Reveco F.(1999), Model for Estimation of Human Exposure to Copper in Drinking Water, The Science of the Total Environmental, 239, 49-70.

Xiao W., Taylor J., Hong S. and Shi B. (2004), Simulation of Copper Release in Pipe Distribution System and Copper Rule Compliance, Florida Water Resources Journal, 9, 14-20.

Kirmeyer G., Murphy B., Sandvig A., Korshin G.V., Shaha B., Fabbricino M. and Burlingame G. (2004) Post-Optimization Lead and Copper Control Monitoring Strategies, IWA Publishing London, UK. 